\title{
Uso e impactos de fontes hídricas em região semiárida: um estudo de caso no assentamento Novo Assunção em Aracoiaba, Ceará
}

Desde os primórdios da humanidade a água se mantém como um dos principais recursos para a sustentação da vida na Terra. Nessa perspectiva, os estudos sobre os recursos hídricos tornam-se de extrema importância, principalmente em regiões áridas e semiáridas, onde a água encontra-se limitada. Nesse contexto, esta pesquisa tem como objetivo avaliar as fontes hídricas disponíveis em região semiárida, com um estudo de caso no assentamento Novo Assunção no município de Aracoiaba, Ceará. Além de apresentar os principais usos e como estes impactam na qualidade e quantidade da água local. Para essa pesquisa aplicou-se um questionário a fim de identificar o uso da água dos recursos e análises in loco para identificação visual das atividades potencialmente poluidoras e degradadoras. Identificaram-se duas fontes hídricas no Assentamento, um açude e um rio. Percebeu-se que as tipologias de uso da terra no entorno do açude, consiste em vegetação nativa, solo exposto e a mata ciliar do recurso. Os indicadores de erosão do solo identificaram uma variação de baixa à média vulnerabilidade. Já no segmento fluvial, identificou-se o uso da água para irrigação de hortaliças em canteiros e dessedentação de animais. Mapeou-se 4 classes de uso e ocupação do solo na Área de Proteção Permanente (APP) do rio, sendo elas, área de roçado, área de hortaliças, curral e áreas de solo exposto. As análises na água do rio, indicaram que os parâmetros Condutividade Elétrica (CE), turbidez e Sólidos Totais Dissolvidos (STD) apresentaram altas variações aos padrões de potabilidade principalmente no ponto 2 .

Palavras-chave: Geotecnologias; Recursos hídricos; Potencial de contaminação.

\section{Use and impacts of water sources in a semi-arid region: a case study in the New Assumption settlement in Aracoiaba, Ceará}

Since the dawn of humanity, water has been one of the main resources for sustaining life on Earth. In this perspective, studies on water resources become extremely important, especially in arid and semi-arid regions, where water is limited. In this context, this research aims to evaluate the water sources available in the semiarid region, with a case study in the Novo Assunção settlement in the municipality of Aracoiaba, Ceará. In addition to presenting the main uses and how they impact the quality and quantity of local water. For this research, a questionnaire was applied in order to identify the use of water resources and analyzes in loco for visual identification of potentially polluting and degrading activities. Two water sources were identified in the Settlement, a weir and a river. It was noticed that the land use typologies around the weir, consists of native vegetation, exposed soil and the resource riparian forest. The indicators of soil erosion identified a variation from low to medium vulnerability. In the fluvial segment, the use of water for irrigation of vegetables in beds and animal feed was identified. Four classes of land use and occupation were mapped in the Permanent Protection Area-APP of the river, namely, the swidden area, vegetable area, corral and exposed soil areas. The analyzes in the river water indicated that the parameters Electrical Conductivity (EC), turbidity and Total Dissolved Solids (STD) showed high variations in the potability standards, mainly in point 2.

Keywords: Geotechnologies; Water resources; Contamination potential.

Topic: Uso de Recursos Naturais

Reviewed anonymously in the process of blind peer.

Antônio Patrick Meneses de Brito ic

Universidade da Integração Internacional da Lusofonia Afro-Brasileira, Brasil http://lattes.cnpq.br/1438594906771448

http://orcid.org/0000-0002-8473-2617

patrickmeneses675@gmail.com

Ítalo Magno de Melo Santos (iD)

Universidade da Integração Internacional da Lusofonia Afro-Brasileira, Brasil http://orcid.org/0000-0002-9083-8450

http://lattes.cnpq.br/4960651222607037

iitalomagno@gmail.com

Olienaide Ribeiro de Oliveira Pinto (it)

Universidade da Integração Internacional da Lusofonia Afro-Brasileira, Brasil http://lattes.cnpq.br/8216617581480616

http://orcid.org/0000-0002-8333-3665

agron.olienaide@gmail.com

detis

DOI: 10.6008/CBPC2237-9290.2021.002.0011
Received: 03/04/2021

Approved: 01/05/2021

Maria Gorete Flores Salles (ib

Universidade da Integração Internacional da Lusofonia Afro-Brasileira, Brasil http://lattes.cnpq.br/7276641106153452

http://orcid.org/0000-0002-0754-9405

gorete@unilab.edu.br

Ciro de Miranda Pinto

Universidade da Integração Internacional da Lusofonia Afro-Brasileira, Brasil http://lattes.cnpq.br/9951861341852271

http://orcid.org/0000-0002-8308-1488

ciroagron@unilab.edu.br

BRITO, A. P. M.; SANTOS, I. M. M.; PINTO, O. R. O.; SALLES, M. G. F.; PINTO, C. M.. Uso e impactos de fontes hídricas em região semiárida: um estudo de caso no assentamento Novo Assunção em Aracoiaba, Ceará. Natural Resources, v.11, n.2, p.104-116, 2021. DOI: http://doi.org/10.6008/CBPC2237-9290.2021.002.0011 


\section{INTRODUÇÃO}

A água é um dos principais recursos naturais que permite à humanidade sobreviver no planeta Terra. A maior parte do planeta é ocupada por água, entretanto, apenas $0,7 \%$ é caracterizada viável ao consumo humano (BRITO et al., 2019). Em detrimento dos avanços na sociedade, a busca por esse recurso se tornou cada vez mais constante, e atualmente indiscriminada.

Em consequência dessa busca e uso irregular, os recursos hídricos se mantêm entre os bens naturais mais ameaçados e impactados. Diversos são os impactos que incidem diretamente sobre as águas, como o desperdício, contaminação por efluentes e resíduos sólidos, ocupação irregular, remoção da mata ciliar e outros. Tais impactos afetam principalmente a potabilidade (qualidade) dos recursos. Para Silva (2014) é bastante perceptível à existência de dificuldades relacionadas à quantidade, qualidade e distribuição desse bem entre os aglomerados populacionais.

Nessa perspectiva, observa-se outra problemática relacionada aos recursos hídricos, trata-se de sua distribuição entre as diferentes regiões, nesse caso, um problema de origem natural. Sabe-se, que as regiões áridas e semiáridas, caracterizam-se por longos períodos de estiagem, baixa intensidade pluviométrica com distribuição irregular, o que requer maior cuidado as fontes hídricas disponíveis, consequentemente redução máxima dos impactos. Para Nogueira et al. (2009), desde o século XVII a região semiárida tem passado por intenso processo de degradação em seus constituintes ambientais, o que acelera mais ainda o estado de escassez hídrica.

Tendo em vista esses problemas aos recursos hídricos, no Brasil foi criada uma lei que permite a proteção desse bem, o código florestal (BRASIL, 2012), que possui várias medidas conservacionistas e preservacionistas sobre a fauna, flora e os corpos hídricos. Dentre as medidas, apresentam-se os critérios de como deve ser o uso e ocupação as margens dos recursos hídricos, a fim de garantir maior proteção às águas. Outra legislação de proteção é Política Nacional de Recursos Hídricos (PNRH) lei no 9.433.

Nesse contexto, o trabalho tem como objetivo avaliar as fontes hídricas disponíveis em região semiárida em um estudo de caso no assentamento Nova Assunção em Aracoiaba no estado do Ceará. Além de apresentar os principais usos e como estes impactam na qualidade e quantidade da água no local.

\section{METODOLOGIA}

\section{Localização e caracterização da área de estudo}

O assentamento Novo Assunção localiza-se no município de Aracoiaba no estado do Ceará (Figura 1). Está situado especificamente na mesorregião que corresponde ao Maciço de Baturité, entre as coordenadas geográficas 40 22' 16" latitude sul e 38 48' 51" longitude oeste. O assentamento é composto por duas comunidades, Pedra Aguda e Assunção, com extensão territorial de 737,43 ha. A porção que compreende a Pedra Aguda localiza-se a $4^{\circ} 41^{\prime} 90^{\prime \prime}$ de latitude Sul e $38^{\circ} 76^{\prime} 92^{\prime \prime}$ de longitude Oeste, com altitude de $88 \mathrm{~m}$, a comunidade de Assunção encontra-se a $4^{\circ} 25^{\prime}$ de latitude Sul e $38^{\circ} 46^{\prime \prime}$ de longitude oeste, com $73 \mathrm{~m}$ de altitude (MAIA et al., 2019). 


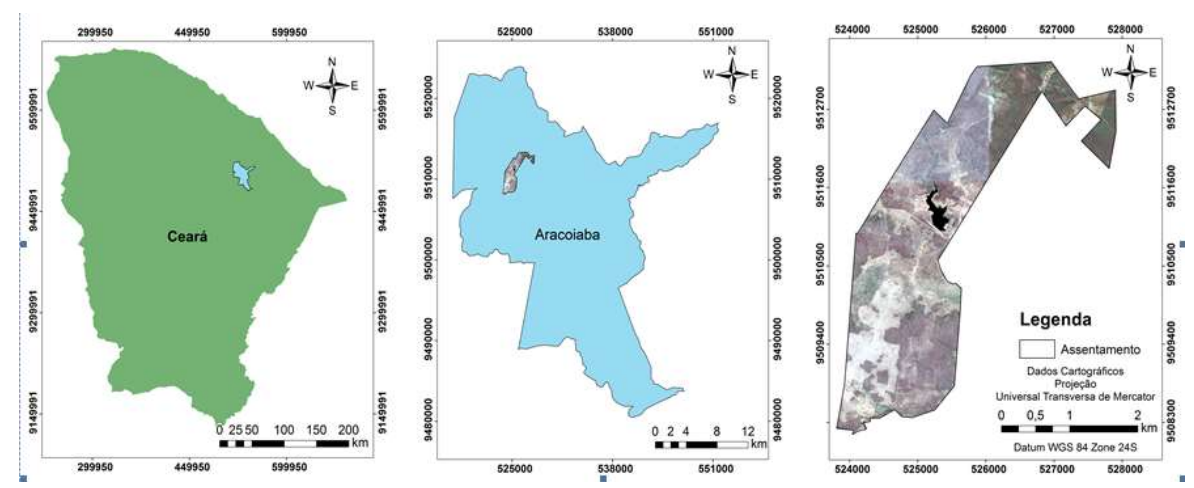

Figura 1: Mapa de localização da área de estudo.

São assentadas 17 famílias no total, 12 na comunidade de Assunção e 5 na Pedra Aguda. A renda é dependente principalmente de atividades agrícolas e pecuárias. As fontes de abastecimento hídrico disponíveis correspondem a um açude, um rio e 17 cisternas de placa, sendo esta última a principal forma de captação e armazenamento da água potável. Ressalta-se que as comunidades não são atendidas por companhia de abastecimento de água municipal/estadual. O assentamento apresenta o código 2301208 no IBGE.

Com base nas características geoambientais, o clima caracteriza-se em Tropical Quente Semiárido, Tropical Quente Semiárido Brando e Tropical Quente Subsumido, com temperaturas que variam de 240 a 260 C. O período chuvoso corresponde aos meses de fevereiro a abril, com precipitação média de 1.010 $\mathrm{mm}$. O relevo é constituído de depressões sertanejo e maciço residual, onde os principais solos classificados são Areias Quartzosas Distróficas, Podzólico Vermelho-Amarelo, Solos Aluviais, Solos Litólicos e Planossolo Solódico. A vegetação é composta por Floresta Subcaducifólia Tropical Pluvial e Caatinga Arbustiva Densa (IPECE, 2017).

\section{Procedimentos metodológicos utilizados}

A delimitação da área de estudo foi realizada por meio de imagem espacial com o auxílio das ferramentas do programa ArcMap 10.3. A identificação das fontes hídricas do assentamento foi realizada mediante identificação in loco. A representação do rio e do açude foi feita mediante a imagem espacial extraída. Aplicou-se na comunidade um questionário semiestruturado, com fins de avaliar as formas de armazenamento da água, principais usos, modo de preservação dos recursos hídricos e convivência com o semiárido.

Para as análises de água, realizou-se a coleta de amostras apenas do rio que tangencia a comunidade de Pedra Aguda, pois essa água é destinada para dessedentação de animais e uso agrícola. Realizaram-se três pontos de coleta (Figura 2), espacializados apenas na extensão de uso pelos assentados.

A coleta e armazenamento das amostras de água foram realizados mediante Ana (2011). As análises foram determinadas no laboratório de química geral da Universidade da Integração Internacional da Lusofonia Afro-brasileira-UNILAB. Foram analisados 5 parâmetros físico-químicos, turbidez, pH, sólidos totais dissolvidos, condutividade elétrica e temperatura. A turbidez foi expressa por turbidímetro AP modelo 2000, o pH em Potencial Hidrogeniônico, Sólidos Totais Dissolvido (STD) e condutividade elétrica 
(CE) foram aferidas por equipamento de bancada condutivímetro AZ -modelo 86505. O parâmetro temperatura (aferido apenas no rio) foi realizado por termômetro de mercúrio.

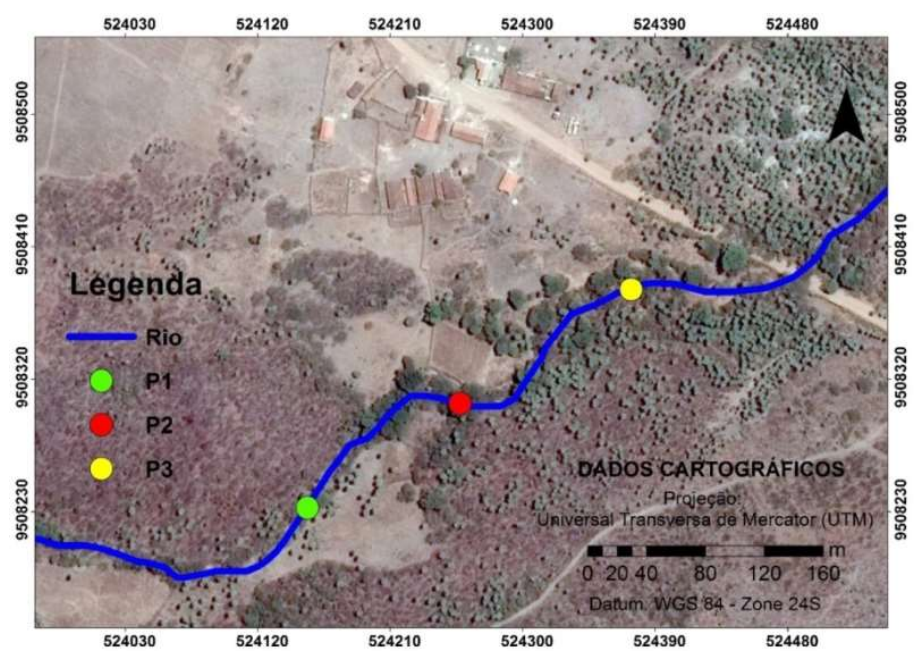

Figura 2: Espacialização dos pontos de coleta de água do rio.

Os STD foram avaliados de acordo com a Portaria no 2.914 (BRASIL, 2011). A condutividade elétrica, e turbidez, baseiam-se em Brasil (2006). Os valores de referência para pH são determinados de acordo com Brasil (2005). A delimitação do açude e espacialização do uso da terra foi realizada no programa ArcGIS. Por meio da ferramenta Image Classification utilizou-se o classificador Maxver (método de classificação por máxima verossimilhança). A classificação considera que as bandas têm distribuição normal para calcular a probabilidade de um dado pixel pertencer a uma classe específica (INPE, 2008).

Para a avaliação da vulnerabilidade a erosão do solo no entorno do açude aplicou-se no mesmo, um índice a partir da metodologia de Ros (2005), o método considera a avaliação de indicadores naturais e antrópicos de erosão do solo (Tabela 1). A elevação do terreno foi obtida por meio da elaboração do mapa de declividade, a partir do modelo numérico do terreno. O mapa de elevação foi realizado no ArcGIS, com uso de imagem espacial. Classificou-se a declividade de acordo com Ross (1994), conforme o Tabela 1.

Tabela 1: Indicadores para análise da vulnerabilidade a erosão.

\begin{tabular}{|c|c|c|c|}
\hline Indicadores & BAIXA (1) & MÉDIA (2) & ALTA (3) \\
\hline Classe de solo & $\begin{array}{l}\text { Podzólico Vermelho- Amarelo, } \\
\text { Planossolo Solódico }\end{array}$ & $\begin{array}{l}\text { Bruno Não-Cálcico, Litólico, } \\
\text { Areia quartzosa }\end{array}$ & $\begin{array}{l}\text { Podzólico Vermelho- Amarelo } \\
\text { Eutrófico, Latossolo vermelho- } \\
\text { Amarelo }\end{array}$ \\
\hline $\begin{array}{l}\text { Condições do solo } \\
\text { (entorno de } 30 \text { metros) }\end{array}$ & Coberto por vegetação & Solo parcialmente coberto & Solo totalmente exposto \\
\hline $\begin{array}{l}\text { Pluviosidade } \\
\text { (mm/mês) }\end{array}$ & $<50$ & 50 a 525 & $>525$ \\
\hline Uso e ocupação da terra & $\begin{array}{l}\text { Vegetação densa, } \\
\text { Mata ciliar }\end{array}$ & Vegetação esparsa & $\begin{array}{l}\text { Solo exposto, } \\
\text { Área irrigada }\end{array}$ \\
\hline Declividade & Até $6 \%$ & 7 a $20 \%$ & $>20 \%$ \\
\hline Atividade agrícola & Não ocorre & $\begin{array}{l}\text { Ocorre sem o uso de } \\
\text { maquinário }\end{array}$ & Ocorre com o uso de maquinário \\
\hline Atividade pecuária & Não ocorre & Intensivo (sem pastejo) & Extensivo (com pastejo) \\
\hline
\end{tabular}

Ros (2005).

O indicador de erodibilidade do solo foi indicado de acordo com o mapa de reconhecimento de 
solos do estado do Ceará (JACOMINE, 1973). A partir do mapa classificou-se a vulnerabilidade a erosão. A classificação seguiu os procedimentos de Freitas (2003), que considera as ordens de solo, atribuindo a elas uma escala de vulnerabilidade.

O indicador intensidade pluviométrica foi determinado e classificado de acordo com a metodologia de Crepani et al. (2004), em que a média anual de precipitação $(\mathrm{mm})$ é dividida pela duração do período chuvoso (meses). Os dados de precipitação diária foram recolhidos na base de dados da FUNCEME. Realizou-se a caracterização média da intensidade pluviométrica considerando os dados dos anos de 2017, 2018 e 2019, para isso a intensidade pluviométrica adotada foi à média entre as intensidades dos três anos.

Para o indicador de uso do solo, realizou-se o mapa de ocupação da terra no entorno de 100 metros do açude, a partir da lâmina d'água. A classificação foi determinada com a extensão "Image Classification" no ArcGIS. Para coleta de dados dos indicadores, condições do solo, atividade agrícola e pecuária foi realizado análise in loco, durante as visitas ao assentamento.

Para a delimitação da Área de Preservação Permanente (APP) do rio que tangencia a comunidade de Pedra Aguda, tomaram-se como base os procedimentos estabelecidos no Código Florestal Brasileiro (BRASIL, 2012). Para representar graficamente a área preservada gerou-se um buffer de 30 metros ao redor do curso hídrico. A classificação das tipologias de uso e ocupação foram expressas por polígonos representativos na imagem georreferenciada. O método consiste na observação de cada classe de ocupação da área de estudo e delimitação manual, por meio da interpretação visual.

\section{RESULTADOS E DISCUSSÕES}

No assentamento Novo Assunção umas das principais problemáticas as questões hídricas, são às formas de manejo e não a escassez de recursos. $O$ assentamento não dispõe de água encanada e nenhuma outra forma de rede de abastecimento. $O$ assentamento possui 2 fontes hídricas (Figura 3), sendo elas um açude na comunidade de Assunção e um rio que tangencia a comunidade de Pedra Aguda.

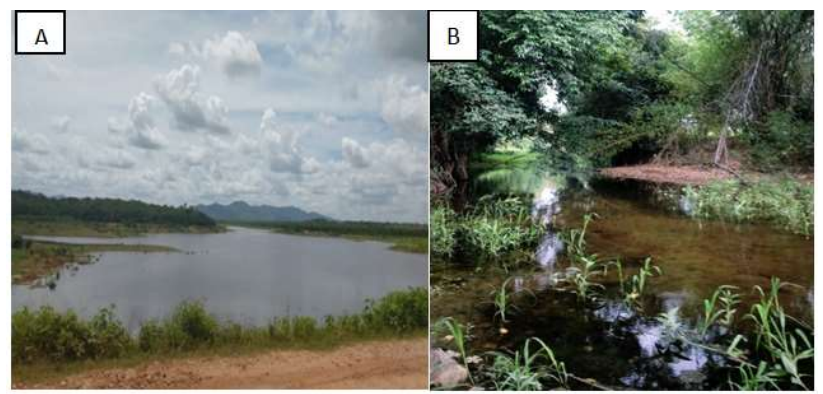

Figura 3: Fontes hídricas disponíveis no assentamento Novo Assunção. Açude na comunidade de Assunção (A); segmento fluvial na comunidade de Pedra Aguda (B).

Além disso, em cada residência do assentamento possui uma cisterna com capacidade de 16.000 litros para armazenamento de água no período de chuvas que serve para uso doméstico e o consumo humano. 


\section{Uso da água e ocupação da terra: potencial de vulnerabilidade a erosão}

Identificou-se que a água do açude não é utilizada para fins de consumo humano, dessedentação animal ou outras formas de uso doméstico. Com base nos questionamentos aos moradores da comunidade de Assunção (onde o recurso se localiza), as cisternas presentes nas residências são suficientes para o abastecimento. Como não há criação de animais em grande quantidade pelos moradores da comunidade, não é preciso o uso da água para esta finalidade.

Verificou-se (mediante análise in situ e imagem espacial) que nas proximidades do açude, tanto a área de várzea quanto o entorno de 100m, não há nenhuma instalação agrícola, o que se observou foi a possibilidade de uso da água para irrigação ou para outras finalidades agrícolas. Outra forma de aproveitamento do uso da água do açude e o recurso em si seriam para criação de peixes, porém, constatou-se que o determinado uso também não é realizado.

O potencial hídrico disponível no reservatório não é aproveitado. Assim, entende-se que o mesmo desempenha no assentamento um papel muito importante no que diz respeito à segurança hídrica local, pois em um dado momento em que as cisternas percam capacidade (por escassez pluviométrica, por exemplo) o açude pode ser uma opção de uso. Salienta-se que para o uso dessa água para consumo humano, devem-se realizar análises da qualidade e também os procedimentos de tratamento subsequentes. Reafirma-se que não foram realizadas análises na água para uma caraterização prévia, pois não há evidencias de consumo.

De acordo com a classificação realizada (Figura 4), identificou-se que a maior tipologia de ocupação no entorno do reservatório consiste na classe de vegetação nativa (mata densa), correspondendo a 32\% da área total (Tabela 2). Percebeu-se que essa classe concentrou-se na região norte da área analisa caracterizando maior estado de conservação vegetal. A segunda maior concentração especializa-se na região sudeste, com manchas ao sul, entre as áreas de solo exposto.

A segunda maior ocupação do terreno corresponde à classe de solo exposto ( $13,5 \%$ da área), mediante a imagem pode-se perceber que essas áreas margearam grande parte do recurso. Observou-se uma grande concentração na região noroeste e nordeste. Salienta-se que as áreas de solo exposto correspondem a algumas estradas de acesso e também áreas desmatas para extração madeireira (outra fonte de renda de alguns assentados). Como a vegetação nativa é constituída predominantemente por arbustos e árvores espaçadas (caatinga), a prática extrativista apresenta grande severidade, desencadeando grandes áreas de supressão vegetal. Corroborando com Mendonça e Marques (2011) as perdas nas propriedades ambientais causadas pela ocupação irregular podem apresentam reflexos tanto na quantidade quanto na qualidade hídrica de um recurso.

Outra prática que pode contribuir para a aparição de solo exposto é a atividade agrícola por sequeiro (prática muito comum na região), plantação de milho e feijão em sistemas de roçados durante o período chuvoso (sem uso de irrigação). Desse modo, essas áreas acabam perdendo o vigor vegetativo natural (devido a práticas como desmatamento, destoca, queima) desenvolvendo áreas descobertas principalmente no período seco. 


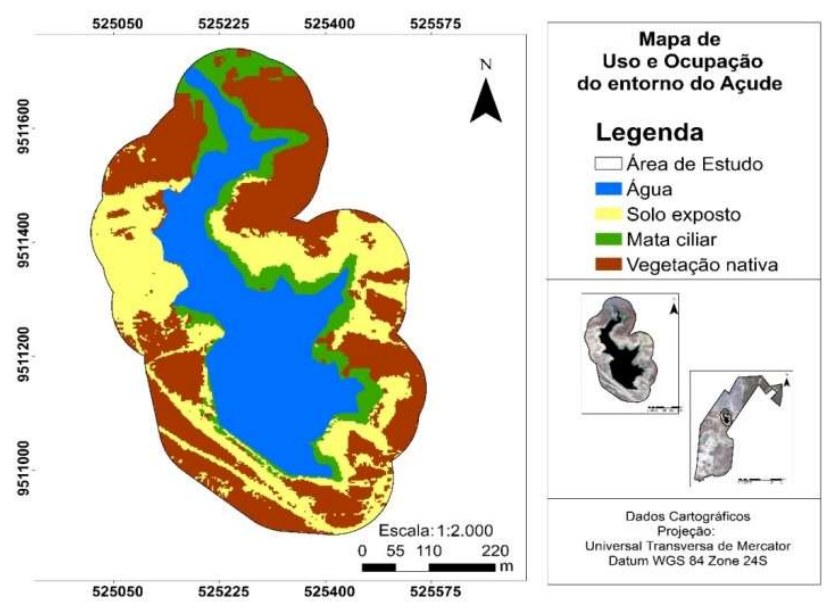

Figura 4. Distribuição espacial do uso e ocupação da terra no entorno do reservatório.

Tabela 2: Quantitativo das classes de uso e ocupação do solo no entorno do açude.

\begin{tabular}{llll}
\hline Ocupação da terra & Área da classe $\left(\mathrm{km}^{2}\right)$ & Perímetro da classe $(\mathrm{km})$ & \% de ocupação \\
\hline Vegetação nativa & 0,112 & 15,7 & 32 \\
Solo exposto & 0,082 & 13,5 & 23,5 \\
Mata ciliar & 0,068 & 10 & 19,5 \\
Espelho d'água & 0,088 & 2,5 & 25 \\
\hline Total & 0,350 & 41,7 & 100 \\
\hline
\end{tabular}

Observou-se que a menor ocupação natural da área correu para a mata ciliar. Essa classe apresenta-se em áreas úmidas que ficam próximo ao espelho d’água. Notou-se que ela se espacializa a margem de quase todo o reservatório, porém em alguns locais essa classe foi substituída pelo solo exposto, como pode ser observado principalmente na região noroeste. Em concordância com Brasil, (2012) essas áreas têm como principal função preservar o recurso hídrico. Na imagem (Figura 4), identifica-se que a mata ciliar se concentra na região norte, devido ao fato de ser a área do córrego que abastece o açude, portanto área úmida.

O indicador classe de solo apresentou baixa vulnerabilidade à erosão (Tabela 3). De acordo com a classificação, a tipologia de solo inserida na área do reservatório apresenta um baixo risco para os intemperes naturais e/ou antrópicos. Para Cunha e Guerra (2003) essa classe de solo apresenta uma boa agregação e estruturação das partículas. Por apresentar material de origem diferente, propriedades físicas e químicas, processos de formação diferentes, as ordens de solo apresentam naturalmente caraterísticas que os tornam mais ou menos suscetíveis a degradação.

Tabela 3: Resultados dos indicadores para análise da vulnerabilidade a erosão.

\begin{tabular}{ccc}
\hline Indicadores & Classificação da vulnerabilidade & Descrição \\
\hline Classe de solo & Baixa & Argissolo (Podzólico Vermelho - Amarelo) \\
Condições do solo & Média & Solo parcialmente coberto \\
Intensidade Pluviométrica (mm/mês) & Média & 80,8 \\
Uso e ocupação da terra & Média & Vegetação esparsa \\
Declividade & Baixa & Até $6 \%$ \\
Atividade agrícola & Baixa & Não ocorre \\
Atividade pecuária & Baixa & Não ocorre \\
\hline
\end{tabular}

Outro fator que afeta diretamente a erosão do solo e consequentemente contribui para a formação de áreas degradadas é a cobertura vegetal (que garantem sustentação e estabilização aos agregados) 
inserida nesse solo. Por tanto se entende que solos desnudos, sem vegetação, são mais impactados pelos processos erosivos (como chuvas e vento), aumentado às taxas de escoamento superficial e também a percolação da água infiltrada nos horizontes do solo. Identificou-se que o indicador condições do solo apresentou baixa vulnerabilidade a erosão, pois, o solo local encontra-se parcialmente coberto por vegetação.

A intensidade pluviométrica identificada classificou-se em média vulnerabilidade $(80,8 \mathrm{~mm} / \mathrm{mês})$. A quantidade de chuva que incide em uma local afeta diretamente as propriedades físicas do solo, principalmente o que se refere a sua estrutura. A alta precipitação associado à desproteção do solo, favorece a erosão, consequentemente aumentando as perdas tanto em quantidade como em qualidade (fertilidade).

Para o indicador uso e ocupação da terra, a vulnerabilidade foi classificada como média. Pois a maior ocupação da área de entorno do reservatório corresponde à vegetação esparsa. A declividade do terreno apresentou baixa vulnerabilidade (até 6\%). Salienta-se que a topografia do terreno afeta diretamente nas taxas de perda de solo, pois influi no escoamento superficial em detrimento da gravidade. Para Bertoni et al. (2014) a perda de solo por unidade de área em declive qualquer corresponde a uma parcela unitária de $25 \mathrm{~m}$ de comprimento em $9 \%$ de declividade.

Os indicadores atividade agrícola e pecuária apresentaram baixa vulnerabilidade, pois não ocorrem na área. Ambas as atividades contribuem para o revolvimento do solo e também aumenta os níveis de compactação, tanto pelas atividades de manejo quanto pelo pisoteando animal. Dessa forma, entende-se que as caraterísticas geoambientais e as ações antrópicas apresentam taxas de vulnerabilidade a erosão do solo, que em determinadas intensidades podem desencadear problemas ao reservatório, como formação de áreas degradas, supressão da mata nativa e assoreamento. Portanto, identificou-se que as características naturais do açude associadas às formas de uso, apresenta um potencial de baixa à média vulnerabilidade ao recurso.

O rio que tangencia o assentamento adentra a comunidade de Pedra Aguda pela porção oeste do município (Figura 5) sendo ele um afluente que desagua no Rio Aracoiaba. Observou-se que a água do rio é utilizada pelos assentados para as atividades agrícolas e pecuárias.
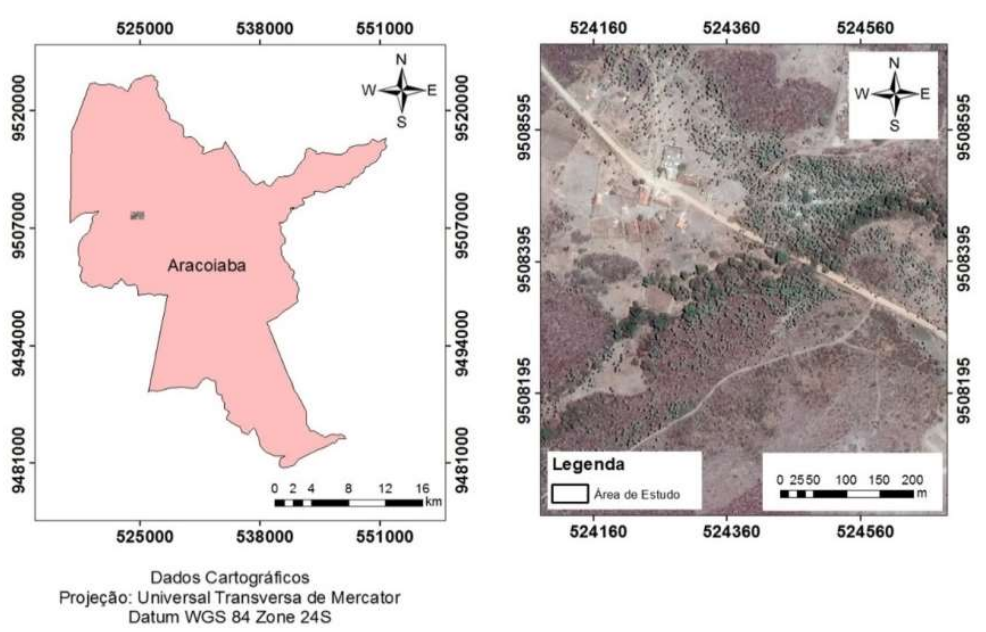

Figura 5: Representação do rio que tangencia a comunidade de pedra aguda. 


\section{Caracterização da ocupação do solo na APP do rio}

De acordo com a espacialização realizada, identificou-se 4 classes de uso e ocupação do solo na área analisada. Sendo elas, área agrícola com implantação de roçado, área de hortaliças com plantação em canteiros, curral para contenção de bovinos e áreas de solo exposto (Figura 6). Observou-se que as classes de uso da terra apresentaram maior concentração na parte superior da imagem, na região Norte da APP.

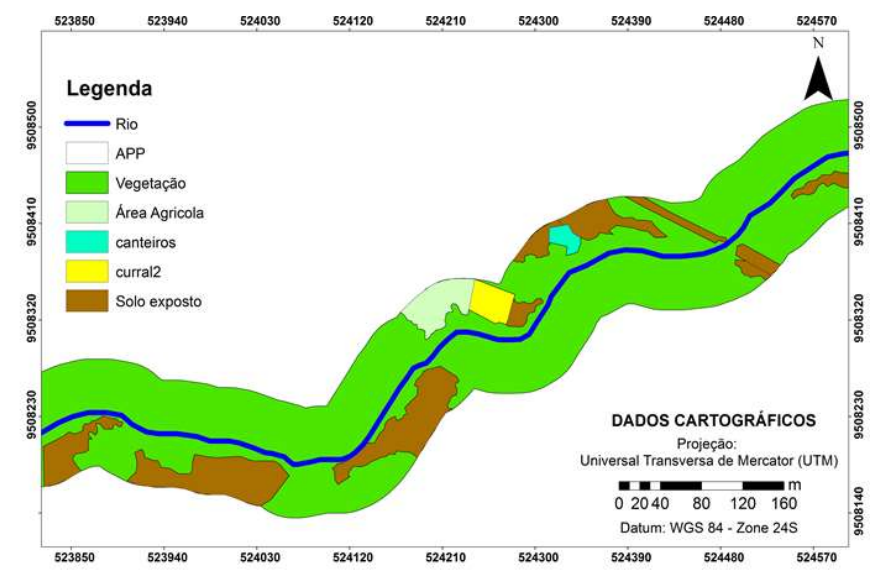

Figura 6: Espacialização das classes de uso e ocupação da terra na APP do rio.

Mediante as classes identificadas, percebeu-se que dentre os usos na margem do rio, destacou-se o solo exposto, que pode estar fortemente associado às atividades agropecuárias comum no assentamento. O solo exposto na maioria de sua aparição representa uma área destinada a cultivos ou pasto em tempos anteriores. A remoção da mata ciliar de um rio pode contribuir para aparição do assoreamento no córrego, em níveis mais severos pode inviabilizar o uso do recurso em determinados trechos. Dessa forma considera essa uma prática muito perigosa, principalmente em regiões semiáridas onde os recursos hídricos se apresentam bastante necessários.

O segundo maior uso da terra na área do rio, se deu para o uso agrícola, o cultivo em forma de roçado (Figura 7-C). Nesse trecho observou-se que a mata nativa foi substituída por culturas agrícolas perenes e anuais. Identificou-se que o plantio é realizado apenas para fins de subsistência e não há indícios de comercialização dos produtos cultivados.

Observou-se que o curral dos bovinos localiza-se bem próximo ao leito do rio, com valas em declividade em direção ao rio (parte de menor elevação nessa área). Em períodos de chuva todo o material produzido no curral (fezes, urina e outros efluentes) descarrega-se dentro do córrego, o que pode afetar a qualidade de parâmetros da água.

Percebeu-se que as classes de uso da terra, distribuíram-se bem próximas ao trecho do rio, pois todas necessitam do uso da água para seu funcionamento. A utilização da água do rio para as atividades destacadas se faz de forma manual, a coleta tanto para regar os canteiros quanto para dessedentação animal no curral é feita com recipientes. 

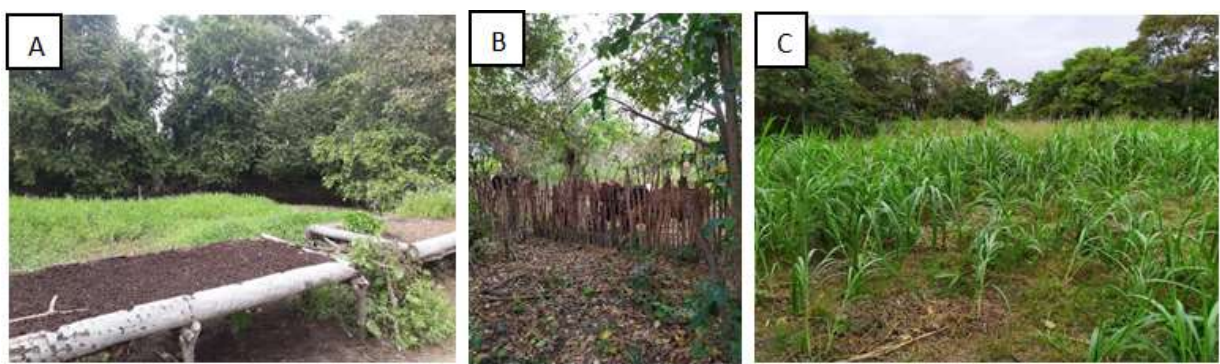

Figura 7: Exemplos de classes de uso da terra, identifcados. Cutivo de hortaliças em canteiros(A); curral para contenção de bovinos(B); cultivo em roçado.

\section{Análise físico-química da água}

Observou-se que as amostras de água coletadas no rio apresentaram valores superiores ao permitido em 4, dos 5 parâmetros físico-químicos avaliados.
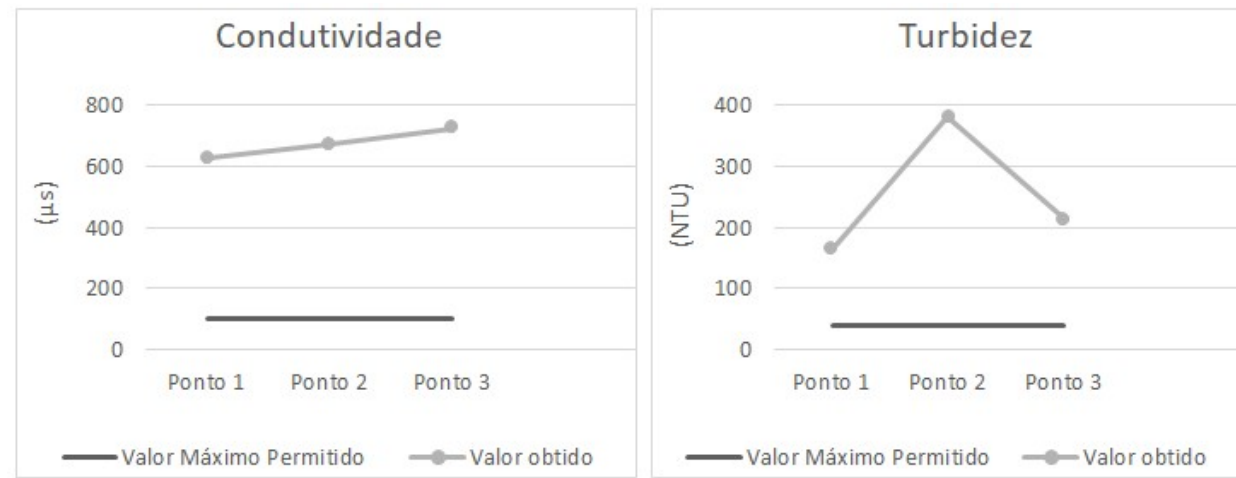

Figura 8: Resultados dos parâmetros CE e turbidez.

Para o parâmetro de condutividade elétrica (Figura 8), observou-se o ponto 3 apresentou o valor mais elevado, concentração 7 vezes maior $(725 \mu \mathrm{s})$, seguido do ponto 2 (674 $\mu \mathrm{s})$ e P1 (628 $\mu \mathrm{s})$. De acordo

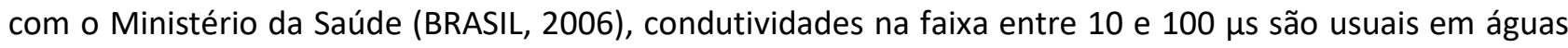
naturais, em águas poluídas esse valor pode chegar até $1000 \mu \mathrm{s}$.

Com relação à turbidez, a amostra que apresentou valor mais elevado foi P2 (380 NTU), valor quase 10 vezes maior que o estabelecido (Figura 8). Em seguida apresentou-se o P3 (215 NTU) e P2 (166 NTU). Em que o valor máximo estabelecido é 40 NTU. A turbidez pode ser provocada por plâncton, algas, detritos orgânicos e outras substâncias, como zinco, ferro, compostos de manganês e areia, resultantes do processo natural de erosão ou da adição de despejos domésticos ou industriais (BRASIL, 2006). De modo geral, observou-se que o rio apresentou água muito turva.

O parâmetro STD apresentou valores em conformidade ao estabelecido apenas no ponto 1 (871 Mg/L). O P2 (1037 Mg/L) e P3 (1374 Mg/L), apresentaram valores acima do valor máximo estabelecido (1000 Mg/L). Esse parâmetro determina a presença de partículas sólidas dissolvidas na água, que pode interferir em outros parâmetros, como cor aparente, turbidez e condutividade elétrica (BRITO et al., 2019). Esses sólidos podem apresentar origem natural (por meio da erosão) ou antrópica.

$\mathrm{O}$ pH apresentou valores alterados no ponto $3(9,48)$ e $2(9,50)$, desse modo a água nos respectivos pontos classificaram-se em alcalinas (Figura 9). Apenas o ponto 1 ajustou-se ao estabelecido $(8,55)$. $\mathrm{O} \mathrm{pH}$ em escala determina a intensidade das condições ácidas ou alcalinas do meio líquido (BRASIL, 2014). Assim, 
a medição desse atributo é de suma importância no rio, pois ele pode inviabilizar o uso da água para irrigação, dessedentação animal e outros usos no assentamento.

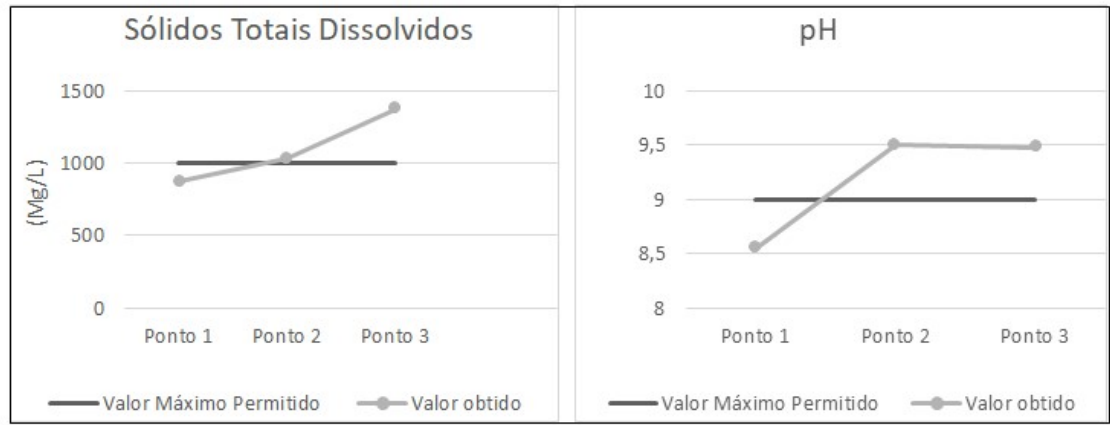

Figura 9: Resultados dos parâmetros STD e pH.

O parâmetro temperatura (20 e $21^{\circ} \mathrm{C}$, mínimo e máximo) se comportou em conformidade com o valor máximo permitido em todos os pontos de análise (Figura 10). A temperatura aumenta em cursos hídricos caso algum composto químico seja despejado diretamente no rio e também em locais cuja mata ciliar seja severamente desmatada fazendo com que a insolação incida diretamente no espelho d'água. Esse aquecimento nas águas pode ocasionar um desequilíbrio na vida aquática.

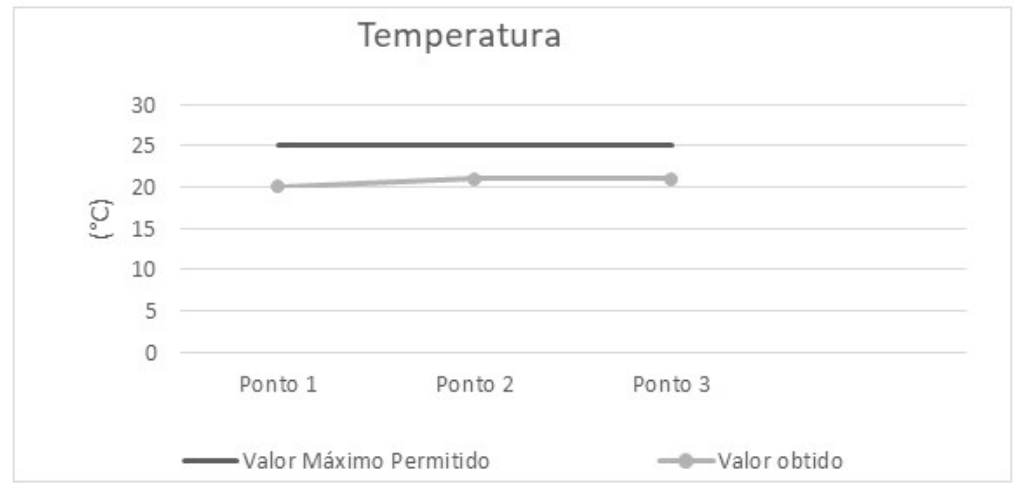

Figura 10: Resultados do parâmetro temperatura.

É provável que os valores elevados no ponto 2 e 3 tenham relação com a presença do curral entre os dois pontos. As águas destes locais apresentam elevadas quantidades de matéria orgânica, outros sólidos e substâncias, devido aos detritos do curral que são descartados dentro do rio. Observou-se que nesses dois pontos a lâmina superficial do rio apresenta-se totalmente coberta por vegetação aquática (Figura 11), sendo considerado um indicador de eutrofização da água.
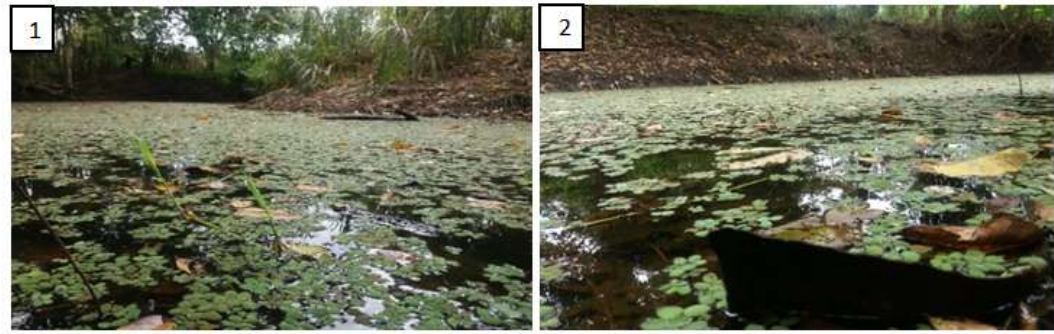

Figura 11: Vegetação aquática na superfície do rio, nos pontos 2 e 3 


\section{CONCLUSÕES}

O uso das ferramentas de geotecnologias permitiu a espacialização das fontes hídricas do Assentamento e a representação das formas de uso potencialmente poluidoras desses recursos. No que pode auxiliando em tomadas de decisões para gestão hídrica local. Identificou-se que a área de estudo, apresenta as questões hídricas como uma das principais problemáticas, entretanto, evidenciou-se que o problema estar fortemente relacionado às formas de manejo e não a escassez de recursos. Uma vez que a água disponível apresenta potencial para suprir as necessidades das comunidades.

De acordo com o questionário realizado, foi identificado que a água do açude não é utilizada para fins de consumo nem agropecuária, apenas para atividades recreativas. Mediante a classificação realizada, percebeu-se que tipologia de uso da terra ao redor do recurso consiste em vegetação nativa, solo exposto e a mata ciliar do açude. Os indicadores de erosão do solo nos arredores do recurso identificaram variação de baixa à média vulnerabilidade a erosão.

O segmento fluvial apresenta como único uso as atividades agropecuárias, cujas águas são destinadas a irrigação de hortaliças em canteiros e dessedentação de animais. Identificou-se 4 classes de uso e ocupação do solo na APP do rio. Sendo elas, área de roçado, área de hortaliças, curral e áreas de solo exposto. As análises na água do rio fez-se perceber que os parâmetros $\mathrm{CE}$, turbidez e STD, apresentaram altas variações aos padrões de potabilidade, caso esse uso seja adotado pelos assentados, faz necessário um tratamento prévio.

Contudo, conclui-se que algumas medidas devem ser tomadas para a proteção das fontes hídricas disponíveis, como por exemplo, redução das áreas de solo exposto aos arredores do açude e consequente reflorestamento das áreas, diminuição da ocupação na APP do rio, desvio dos efluentes proveniente do curral, entre outras. Para que assim, ocorra à conservação dos recursos e em tempos de crise hídrica, o assentamento apresente condições de sustentar os usos essências.

\section{REFERÊNCIAS}

BERTONI, J.; LOMBARDI NETO, F.. Conservação do solo. 9 ed. São Paulo: Ícone, 2014.

ANA. Agência Nacional das Águas. Guia nacional de coleta e preservação de amostras. Brasilia, 2011.

BRASIL. Resolução $\mathbf{N}^{\circ}$ 357. Dispõe sobre a classificação dos corpos de água e diretrizes ambientais para o seu enquadramento, bem como estabelece as condições e padrões de lançamento de efluentes, e dá outras providências. Brasília: DOU, 2005.

BRASIL. Decreto $\mathbf{n}^{\circ}$ 12.651. Dispõe sobre a proteção da vegetação nativa. Brasília: DOU, 2012

BRASIL. Portaria no 2.914. Dispõe sobre os procedimentos de controle e de vigilância da qualidade da água para consumo humano e seu padrão de potabilidade. Brasília: DOU, 2011.

SECRETARIA DE VIGILÂNCIA EM SAÚDE. Vigilância e controle da qualidade da água para o consumo. Brasília, 2006.
BRITO, A. P. M.. Espacialização da rede de efluentes despejada no rio Pacoti, trecho Redenção e análise da qualidade da água. REDE - Revista Eletrônica do PRODEMA, v.13, n.1, p.124-143, 2019. DOI: https://doi.org/10.22411/rede2019.1301.11

BRITO, A. P.. Distribuição espacial das nascentes e análise da qualidade da água na comunidade olho d'água dos Constantinos, em Redenção, Ceará. In: SIMPÓSIO REGIONAL DE GEOPROCESSAMENTO. Anais. Teresina, 2019.

CREPANI, E.; MEDEIROS, J. S.; PALMEIRA, A. F.. Intensidade pluviométrica: uma maneira de tratar dados pluviométricos para análise da vulnerabilidade de paisagens à perda de solo. São José dos Campos: Inpe, 2004.

CUNHA, S. B.; GUERRA, A. J. T.. Geomorfologia do Brasil. 3 ed. Rio de Janeiro: Bertrand Brasil, 2003.

FREITAS, J. C. A.. Mapeamento da erodibilidade do Ceará a partir de mapas pedológicos. Monografia (Bacharelado em 
Engenharia Civil) - Universidade Federal do Ceará: Fortaleza, 2003.

FUNASA. Fundação Nacional de Saúde. Manual prático de análise de água. 4 ed. Brasília: Funasa, 2013.

IPECE. Instituto de Pesquisa e Estratégia Econômica do Ceará. Perfil básico de Aracoiaba-CE. Fortaleza, 2017.

JACOMINE. P. K. T.. Levantamento exploratório:

reconhecimento de solos do Estado do Ceará. Recife, 1973.

MAIA, A. K. A.. A implantação da caprinocultura leiteira no assentamento Nova Assunção, Aracoiaba-CE. Agrarian

Academy, v.6, n.11, p.1-14, 2019.

MENDONÇA, F.; MARQUES, G. S.. Degradação ambiental e qualidade da água em bacia hidrográfica de abastecimento público - Rio Timbú - PR. Entre Lugar, v.1, n.3, p.11-136, 2011.

NOGUEIRA, F. R. B.; SIMÕES, S. V. D.. Uma abordagem sistêmica para a agropecuária e a dinâmica evolutiva dos sistemas de produção no nordeste semi-árido. Revista Caatinga, v.22, n.2, p.1-6, 2009.

ROSS, J. L. S.. Análise empírica da fragilidade ambiental dos ambientes naturais e antropizados. Revista do Departamento de Geografia (USP), n.6, p.63-74, 1994

ROSS, J. L. S.. Geomorfologia: ambiente e planejamento. São Paulo: Contexto, 2005.

SILVA, D. D.. Falta de saneamento básico e as águas subterrâneas em aquífero freático: região do Bairro Pedra Noventa, Cuiabá (MT). Eng. Sanit. Ambient., v.19, n.1, p.4352, 2014.

A CBPC - Companhia Brasileira de Produção Científica (CNPJ: 11.221.422/0001-03) detém os direitos materiais desta publicação. Os direitos referem-se à publicação do trabalho em qualquer parte do mundo, incluindo os direitos às renovações, expansões e disseminações da contribuição, bem como outros direitos subsidiários. Todos os trabalhos publicados eletronicamente poderão posteriormente ser publicados em coletâneas impressas sob coordenação da Sustenere Publishing, da Companhia Brasileira de Produção Científica e seus parceiros autorizados. Os (as) autores (as) preservam os direitos autorais, mas não têm permissão para a publicação da contribuição em outro meio, impresso ou digital, em português ou em tradução. 